\title{
CRESCIMENTO DE MUDAS DE Campomanesia adamantium (Cambess.) O. Berg (guavira), SUBMETIDAS A TRÊS NÍVEIS DE SOMBREAMENTO E SUBSTRATOS ${ }^{1}$
}

\author{
ANA CRISTINA ARAÚJO AJALLA², MARIA DO CARMO VIEIRA ${ }^{3}$, \\ EDIMILSON VOLPE ${ }^{4}$, NÉSTOR ANTONIO HEREDIA ZÁRATE $^{3}$
}

RESUMO -O experimento foi desenvolvido em Campo Grande - MS, no período de março de 2008 a janeiro de 2009. O objetivo foi avaliar o desenvolvimento das mudas da Campomanesia adamantium (Cambess.) O. Berg. sob três condições de sombreamento e seis substratos. Os tratamentos foram três níveis de sombreamento $(0 \%, 30 \%$ e $50 \%$ de sombra) e seis substratos [100\% de solo Latossolo Vermelho distrófico textura argilosa - LVd (ta); 100\% de solo de Latossolo Vermelho distrófico textura média LVd (tm); 75\% de LVd (ta) + 15\% de areia $+10 \%$ de cama de frango semidecomposta - LVd (ta) + CF $; 75 \%$ de $\mathrm{LVd}(\mathrm{tm})+15 \%$ de areia $+10 \%$ de cama de frango semidecomposta - LVd (tm) + CF; 75\% de LVd(ta) $+15 \%$ de areia $+10 \%$ Organosuper® - LVd (ta) + OR; 75\% de LVd (tm) $+15 \%$ de areia $+10 \%$ de Organosuper ${ }^{\circledR}$ LVd (tm) + OR]. O delineamento experimental foi em blocos ao acaso, arranjado em parcelas subdivididas com medidas repetidas no tempo. Foram utilizadas três repetições e dez plantas por subparcela. Os níveis de sombreamento interferiram do desenvolvimento das mudas nas características de diâmetro do coleto (maior sob sol), área foliar (maior sob 50\% de sombra) e massa seca de raízes (maior sob sol). Considerando o desenvolvimento da parte aérea das mudas, a observação de que sob sol pleno há necessidade de utilização de maior volume de irrigação e que houve menor sobrevivência de plantas, considera-se o nível de sombreamento de $50 \%$ como mais adequado para produção de mudas de guavira. Dos substratos testados, o LVd (ta) foi considerado o mais adequado ao desenvolvimento das mudas pela percentagem de plantas vivas $(95,55 \%)$ sem diferir do LVd (tm) $(98,88 \%)$, maior altura de plantas observada no desenvolvimento e na altura final, maior massa seca de raízes, diferindo estatisticamente dos demais substratos e maior IQD $(2,62)$, sem diferir de $\operatorname{LVd}(\mathrm{tm})(1,50)$. Termos para indexação: Plantas nativas, Myrtaceae, plantas medicinais.

\section{SEEDLING GROWTH OF Campomanesia adamantium (Cambess.) O. Berg (guavira), UNDER THREE LEVELS OF SHADE AND SUBSTRATES}

\begin{abstract}
The experiment was conducted in Campo Grande - MS from March 2008 to January 2009. The objective was to evaluate the development of seedlings of Campomanesia adamantium (Cambess.) $\mathrm{O}$. Berg. under three conditions of shading and six substrates. Treatments were three levels of shading ( $0 \%$, $30 \%$ and $50 \%$ shade ) and six substrates [ $100 \%$ Oxisol soil clayey - LVd ( ta ); $100 \%$ Oxisol soil medium texture LVd ( tm ), $75 \%$ of LVd ( ta ) $+15 \%+10 \%$ sand bed - of - semi-decomposed chicken - LVd ( ta ) $+\mathrm{CF}, 75 \% \mathrm{LVd}(\mathrm{tm})+15 \%+10 \%$ sand bed - from - semi-decomposed chicken - LVd ( tm ) $+\mathrm{CF}, 75$ $\% \operatorname{LVd}($ ta $)+15 \%$ sand $+10 \%$ Organosuper ${ }^{\circledR}-$ LVd ( ta ) + OR, $75 \%$ LVd ( tm ) $+15 \%$ sand $+10 \%$ Organosuper $\left.{ }^{\circledR}-\mathrm{LVd}(\mathrm{tm})+\mathrm{OR}\right]$. The experimental design was random blocks, arranged in a split-plot with repeated measures. There were three replicates and ten plants per subplot. The shading levels interfered in plant growth characteristics of the stem diameter (greater under the sun), leaf area (greater under $50 \%$ shade) and dry weight of roots (higher under the sun). Considering the development of the seedlings, the observation that under full sun, there is the need to use higher volume irrigation and plant survival was lower, and considering the level of shading of $50 \%$ more suitable for guavira seedling production. About the substrates, $\mathrm{LVd}$ ( ta ) was considered the most suitable for the seedling growth percentage of live plants (95.55\%) without differing from LVd ( tm ) ( $98.88 \%$ ), higher plant height observed in the development and the final height, higher dry roots differing from the other substrates and greater IQD ( 2.62 ) without differing from the LVd (tm) (1.50).
\end{abstract}

Index terms: Native plants, Myrtaceae, medicinal plants.

${ }^{1}$ (Trabalho 196-13). Recebido em: 17-01-2014. Aceito para publicação em: 15-05-2013.

${ }^{2}$ Doutoranda em Agronomia - UFGD/ AGRAER; bolsista FUNDECT. Rodovia MS 080 Km 10, CEP 79.114-000-Campo GrandeMS. E-mail: anajallaagraer@gmail.com; acaa337@hotmail.com

${ }^{3}$ Professor UGFGD, Bolsista e Produtividade em Pesquisa (CNPq)Rodov. Dourados Itahum Km 12, CEP 79804-970, Dourados - MS. E-mails: mariavieira@terra.com.br; NestorZarate@ufgd.edu.br;

${ }^{4}$ Dr. Pesquisador AGRAER. Rodv. MS 080 Km 10, CEP 79114-000-Campo Grande - MS. E-mail: edvolpeagraer@gmail.com 


\section{INTRODUÇÃO}

As espécies de Campomanesia (Myrtaceae) têm nome popular guavira ou gabiroba e são originárias do Brasil, com grande abundância na região do Cerrado. São encontradas como subarbustos a arbustos decíduos, apresentando altura de 0,5 a $1,5 \mathrm{~m}$; o florescimento geralmente é de agosto a outubro, e a frutificação, de novembro a dezembro (LORENZI et al., 2006).

Seus frutos são consumidos "in natura" ou processados para a fabricação de sorvete, licor, suco e geleia (PAVAN et al., 2009). As folhas e frutos de Campomanesia possuem algumas propriedades medicinais como: anti-inflamatória, antidiarreica e antisséptica das vias urinárias e contra casos de reumatismo (LORENZI et al., 2006), além de apresentarem um efeito inibitório contra Mycobacterium tuberculosis (PAVAN et al., 2009) e atividade antimicrobiana (CARDOSO et al., 2010).

Apesar da popularidade do consumo da guavira em sua região de ocorrência, dados sobre o cultivo ainda são escassos, havendo necessidade de estudos agronômicos da espécie. A propagação da guavira pode ser feita por sementes com índice de germinação de até $80 \%$, devendo ser semeadas logo após a colheita, pois são sensíveis à secagem e ao armazenamento, sendo consideradas recalcitrantes (MELCHIOR et al., 2006; DRESCH et al., 2012).

A produção de mudas é um estudo importante para o cultivo de espécies nativas, sendo o tipo de substrato um dos fatores a serem pesquisados para seu desenvolvimento. Em relação à Campomanesia adamantium, as informações sobre a produção de mudas ainda são incipientes. Costa et al.(2012) avaliaram o desenvolvimento de mudas de guavira por 150 dias a partir da semeadura, em quatro substratos e dois tipos de ambiente protegidos, observaram melhor desempenho nas mudas produzidas sob tela preta e com $80 \%$ de composto orgânico, considerando os resultados do Indice de Qualidade de Dickson (IQD), massa seca da parte aérea e massa seca de raízes.

O nível de luminosidade é fator importante ao desenvolvimento de mudas. A luz é essencial e limitante ao desenvolvimento vegetativo, e as espécies vegetais possuem exigências específicas para seu crescimento. A literatura é escassa em relação à luminosidade no desenvolvimento de mudas de C. adamantium. Costa et al. (2012), avaliando o desenvolvimento de mudas de guavira, somente em ambientes protegidos, observaram maior massa seca e altura de plantas naquelas desenvolvidas sob tela preta em comparação com tela termorrefletora, com $50 \%$ de sombreamento. Por outro lado, Santos et al. (2010), em estudo da influência dos níveis de sombreamento $(0 \%, 18 \%$, $30 \%$ e $70 \%$ ) na produção e no desenvolvimento de mudas de eucalipto (Eucalyptus grandis Hill ex Maiden), observaram maior altura da parte aérea sob sombreamento de $30 \%$ e $50 \%$ e maior diâmetro de coleto e número de folhas sob pleno sol. Podese observar nesses trabalhos o comportamento diferenciado das espécies em relação à sua adaptação à intensidade luminosa.

Para a muda ser considerada de boa qualidade, alguns fatores do desenvolvimento vegetal devem ser considerados, tais como: altura, diâmetro do coleto, formação de raízes, massa seca, área foliar,bem como a relação destes fatores. Por isso existem alguns índices de qualidade de mudas que relacionam estas características, como o IQD. Este índice pode ser considerado um bom indicador (COSTA et al., 2011), por relacionar a robustez e o equilíbrio da distribuição da biomassa (FONSECA et al., 2002), sendo adotado em vários estudos relativos ao desenvolvimento de mudas (BINOTTO et al., 2010; GODOY;ROSADO, 2011; COSTA et al., 2012). Outro indicativo de qualidade são os índices de crescimento, como a razão de área foliar (RAF), área foliar específica (AFE) e razão de peso (massa) da folha (RPF) (BENINCASA, 2003).

A escassez de estudos agronômicos com as espécies de Campomanesia indica a necessidade de pesquisas com os substratos e nível de luminosidade para produção de mudas.

O objetivo deste trabalho foi avaliar o crescimento de mudas de Campomanesia adamantium (Cambess.) O. Berg (guavira), submetidas a três níveis de sombreamento e diferentes substratos.

\section{MATERIAL E MÉTODOS}

O Experimento foi desenvolvido no Centro de Pesquisa e Capacitação da AGRAER (537 m de altitude; 20²5'12'S; 5440'4”W), em Campo Grande-MS, de março de 2008 a janeiro de 2009.

Para a obtenção das mudas, sementes da guavira foram obtidas de frutos colhidos em dezembro de 2007, de plantas nativas da aldeia indígena Lagoinha (Aquidauana-MS). As sementes foram lavadas em água corrente para a eliminação da mucilagem e semeadas logo em seguida, em bandejas de poliestireno expandido, de 128 células, preenchidas com substrato comercial composto com casca de pínus, fibra de coco e vermiculita, e colocadas sob telado com $50 \%$ de sombreamento. 
Em 14 de abril de 2008, quando as plântulas de guavira tinham cerca de $3 \mathrm{~cm}$ de altura, foram transplantadas para os vasos. Foram irrigadas de forma a manter a umidade próxima à capacidade de campo.

Os tratamentos consistiram em três níveis de sombreamento $(0 \%, 30 \%$ e $50 \%$ de sombra) e seis diferentes substratos, sendo eles: 1 - 100\% de solo Latossolo Vermelho distrófico textura argilosa - LVd (ta); 2 - 100\% de solo de Latossolo Vermelho distrófico textura média LVd (tm); 3 - 75\% de LVd (ta) $+15 \%$ de areia $+10 \%$ de cama de frango semidecomposta - LVd (ta) + CF; 4 - 75\% de $\operatorname{LVd}(\mathrm{tm})+15 \%$ de areia $+10 \%$ de cama de frango semidecomposta - LVd (tm) + CF; 5 - 75\% de $\operatorname{LVd}(\mathrm{ta})+15 \%$ de areia $+10 \%$ Organosuper ${ }^{\circledR}$ LVd (ta) + OR; $6-75 \%$ de $\operatorname{LVd}(\mathrm{tm})+15 \%$ de areia $+10 \%$ de Organosuper ${ }^{\circledR}-$ LVd (tm) + OR. $\mathrm{O}$ delineamento experimental foi em blocos ao acaso, arranjado em parcelas subdivididas com medidas repetidas no tempo. Foram utilizadas três repetições e dez plantas por subparcela, totalizando 540 plantas. As plantas foram cultivadas em vasos com capacidade para oito litros.

O solo para a composição dos substratos foi coletado em Campo Grande - MS, em dois locais, em profundidade abaixo de $20 \mathrm{~cm}$ da superfície, sendo o LVd (ta) sob pastagem e o LVd (tm) sob vegetação natural. Em seguida, foi peneirado, separadamente, e misturado aos outros componentes para compor os demais substratos e feitas amostragens para a análise química (Tabela 1).

Os vasos foram colocados sob os telados com $30 \%$ e $50 \%$ de sombreamento e sob sol. Cada telado tinha dimensões de 2,2 $\mathrm{m}$ de altura, 2,0 $\mathrm{m}$ de largura e 3,0 m de comprimento, sendo dispostos à distância de $6,0 \mathrm{~m}$ entre si. Para os tratamentos sob sol, foram adotados retângulos com as mesmas dimensões dos telados

A partir de 30 dias após o transplante (DAT) até 275 DAT, foram feitas avaliações de altura de plantas, a cada 30 DAT, e número de folhas e diâmetro do coleto a cada 60 DAT, sendo que, no mês de dezembro, foram avaliadas mais uma vez, tendo em vista o crescimento rápido das plantas nesse período. Aos 275 dias após o transplante (DAT), foi avaliada a percentagem de sobrevivência e a altura final das plantas, e foram colhidas cinco plantas de cada subparcela, cortando-as rente ao substrato dos vasos. Foram separados as folhas e os caules, sendo avaliadas: área foliar em integrador tipo LICOR 3.000 e as massas secas das folhas e dos caules, após secagem em estufa de circulação forçada de ar a 65 $\pm 2^{\circ} \mathrm{C}$ até massa constante. Os vasos foram pesados e colhidas amostras para a determinação do teor de umidade; em seguida, as raízes das plantas colhidas foram lavadas em água corrente sobre peneira de 1,58 $\mathrm{mm}$ de espessura de malha. As raízes foram secas em estufa de circulação forçada de ar a $65 \pm 2{ }^{\circ} \mathrm{C}$ até massa constante para a avaliação da massa seca de cada vaso. Para a análise de crescimento das plantas, também foram calculadas as componentes razão de área foliar (RAF), área foliar específica (AFE) e razão de peso de folha (RPF) (BENINCASA, 2003):

$\frac{\mathrm{AF}}{\mathrm{MSPA}+\mathrm{MSR}} ; \mathbf{A F E}=\frac{\mathrm{AF}}{\mathrm{MSF}} ; \mathbf{R P F}=\frac{\text { MSF }}{\text { MSPA+MSR }}$;

Como parâmetro de qualidade das mudas, foi calculado o Índice de Qualidade de Dickson (IQD), conforme Costa et al.(2011):

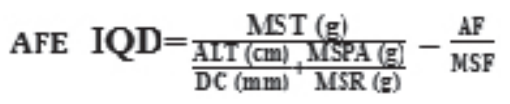

Os dados foram submetidos à análise de variância e regressão. As médias de altura de plantas, número de folhas e diâmetro do coleto foram ajustadas a equações de regressão em função dos dias após transplante. Foi realizada análise de variância com os dados coletados aos 275 DAT (final), sendo as médias comparadas pelo teste de Scott-Knott, a $5 \%$ de probabilidade.

\section{RESULTADOS E DISCUSSÃO}

A análise de variância indicou efeito significativo $(\mathrm{P}<0,05)$ dos sombreamentos, substratos e DAT. Houve interação entre os níveis de sombreamento e dias após transplante (DAT) sobre o diâmetro do coleto, largura e comprimento de folhas; interação entre substrato e DAT sobre a altura de plantas, diâmetro do coleto, número de folhas, largura e comprimento de folhas.

O maior diâmetro do coleto das mudas cultivadas a pleno sol (Figura 1), provavelmente, deve-se à maior atividade fotossintética (REGO; PASSAMAR, 2006). Santos et al. (2010) observaram resultados semelhantes no crescimento de mudas de eucalipto que apresentaram maior diâmetro de coleto sob sol quando comparado com níveis de sombreamento de $18 \%, 30 \%, 50 \%$ e $70 \%$.

A largura e o comprimento das folhas (Figura 2) foram maiores sob sombra $(30 \%$ e $50 \%$, o que reflete a adaptabilidade das plantas a esses níveis de luminosidade. As plantas em geral apresentam capacidade de adaptações durante seu desenvolvimento em função da quantidade e da qualidade de radiação local dominante, e entre essas alterações, estão mudanças na anatomia foliar . A 
ampliação da superfície fotossintética em condições de sombreamento e a diminuição sob maior incidência de luz demonstram que a espécie possui estratégia de alocação de fotoassimilados para a parte aérea quando sombreada, expondo de maneira mais favorável sua superfície fotossintetizante à luz (ENGEL; POGGIANI, 1990).

As plantas desenvolvidas no substrato LVd (ta) foram mais altas (Figura 3a) e com maior diâmetro do coleto (Figura 3 b) em comparação aos demais substratos.

Até aproximadamente os 150 DAT, as alturas das plantas e os diâmetros dos coletos mantinhamse semelhantes nos diferentes substratos (Figuras $3 a$ e $3 b$ ). A partir dessa data, que coincidiu com o aumento da temperatura e da precipitação, observase ampliação nessas diferenças e incrementos no crescimento de altura e de diâmetro do coleto, sendo as maiores no LVd (ta). Essas duas características, associadas ao comprimento e à massa da raiz, são importantes para a definição da qualidade de mudas (BINOTTO, 2007).O número de folhas das plantas de guavira foi maior no substrato LVd (ta) + CF (Figura 3c), sendo o maior número (45,8 folhas/ planta) observado aos 275 DAT.

Considerando-se as curvas de crescimento da altura de plantas e o diâmetro do coleto, o desenvolvimento das mudas foi superior no substrato $\operatorname{LVd}$ (ta) em relação aos demais, indicando que esse tipo de substrato é favorável ao desenvolvimento de mudas de guavira. Além disso, a espécie aparentemente tolera os níveis de sombreamento avaliados, pois não houve diferenças significativas de altura das plantas entre os níveis de sombreamento. Plantas adaptadas ao ambiente de sol, ao serem submetidas ao sombreamento, direcionam a alocação de fotoassimilados para o crescimento em altura, havendo alongamento dos entrenós e produção de folhas delgadas e maiores (LARCHER, 2006).

$\mathrm{Na}$ análise de variância realizada especificamente aos 275 DAT, ocorreram diferenças significativas $(\mathrm{P}<0,05)$ para os níveis de sombreamento na massa seca de raízes, na área foliar, na razão de área foliar (RAF), área foliar específica (AFE) e razão de peso de folha (RPF), efeito dos substratos na altura de plantas, na massa seca de folha, caule e raiz, e no Índice de qualidade de Dickson (IQD).

A maior massa seca de raízes das mudas cultivadas a pleno sol (Tabela 2) pode ter sido em função do menor teor de umidade do solo, combinado com altas temperaturas. As perdas de umidade do solo e da planta provavelmente foram altas, pelo efeito da evapotranspiração. Desta forma, houve a necessidade de maior desenvolvimento radicular para a absorção do menor teor de água disponível. Segundo Larcher (2006), as raízes, em situação de déficit hídrico, crescem permanentemente à procura de água. Resultado semelhante também foi verificado por Ajalla et al. (2012), avaliando o produção de mudas de Baru (Dipteryx alata Vog.) sob diferentes classes texturais de solo (arenosa; média; argilosa; muito argilosa) e níveis de sombreamento $(0 \% ; 30 \%$ e $50 \%$ ); onde, com o aumento do sombreamento, houve diminuição da massa seca de raízes nas mudas sob solo de texturas médias e argilosas. É importante observar que a sobrevivência das mudas em sol pleno foi menor que sob sombra, apesar da não diferença estatística (Tabela 2).

As maiores razões de área foliar (RAF) e área foliar específica (AFE) sob 50\% de sombra (Tabela 2) indicam que, sob sombreamento, houve maior expansão das folhas como adaptação à menor disponibilidade luminosa. Isso porque, à medida que se aumenta o índice de radiação solar, a RAF e AFE diminuem (BENINCASA, 2003), pois a área foliar necessária para a produção de massa seca é menor na maior intensidade luminosa, pela maior produção de fotoassimilados. Resultado semelhante foi verificado por Silva et al. (2006). Os autores, ao avaliarem o desenvolvimento de mudas de maracujazeiro, observaram que, com o aumento do nível de sombreamento $(30 \% ; 50 \%$ e $70 \%$ ), também houve aumento da RAF e AFE em comparação a pleno sol. A razão de peso da folha (RPF) foi menor sob sol em função da maior massa seca de raízes (Tabela 2).

Os dados de desenvolvimento da parte aérea das mudas e a observação da maior sobrevivência sob sombreamento indicam ser este método mais adequado e seguro para a produção de mudas de guavira. Destaca-se que, sob sol pleno, há necessidade de maior volume de irrigação, devido à perda de água pelo processo de evapotranspiração.

A altura no final do período de avaliação foi maior no substrato LVd (ta), porém sem diferir de LVd (tm) e LVd (ta)+CF (Tabela 3). Observa-se, nessa característica, efeito negativo da adição da adubação orgânica na composição dos substratos, apesar do aumento dos níveis de nutrientes e da elevação da saturação por bases (Tabela 1). Esse aumento da disponibilidade de nutrientes é mais marcante no LVd (tm), provavelmente devido ao seu menor poder tampão por ser um solo de textura mais arenosa que o LVd (ta).

As massas secas de caule e de folhas foram maiores nos substratos $\mathrm{LVd}$ (ta), LVd (ta) 
+ CF e LVd (tm) + CF (Tabela 3), cuja diferença para a menor média [LVd (tm) + OR] foi de $66 \%$ e $68 \%$ para massa seca de caule e de folha, respectivamente. Possivelmente, a associação de Organosuper® ao solo mais arenoso seja menos viável do que com o mais argiloso, tendo em vista que, no substrato LVd (ta) + OR, as massas secas de caules e folhas foram maiores. Tal efeito está aparentemente relacionado com as características físicas e químicas diferenciadas desses solos, especialmente pela textura argilosa do solo de Cerrado sob pastagem cultivada, havendo maior capacidade tampão e, provavelmente, pela maior complexação/oclusão da matéria orgânica (SILVA; MENDONÇA, 2007).

A área foliar e número de folhas foram maiores (Tabela 3) no substrato $\mathrm{LVd}$ (ta) $+\mathrm{CF}$ sem diferir do LVd (tm) + OR para o número de folhas. Tendo em vista a altura, massa seca de caule e folha, pode-se considerar que as mudas tiveram bom desenvolvimento aéreo no $\mathrm{LVd}$ (ta) e LVd (ta) + CF. A maior massa seca de raízes foi no substrato LVd (ta) (Tabela 3). Provavelmente, a ocorrência de maior quantidade de microporos nos solos com textura mais argilosa aumente a necessidade de a muda emitir mais raízes para melhor aproveitamento de água e nutrientes, induzindo a maior massa de raízes no $\mathrm{LVd}$ (ta). ). Resultado semelhante foi verificado por Ajalla et al. (2012), que obtiveram maior massa seca de raízes em mudas de baru desenvolvidas em solos de textura argilosa, em comparação aos solos de textura arenosa. Em pastagens cultivadas, tem sido verificado também menor produção de raízes em solos de textura arenosa em relação a solos de classes mais argilosas (VOLPE et al., 2008). Considerando a importância de raízes bem desenvolvidas para a implantação das mudas em campo, aliado com o desenvolvimento aéreo, o LVd (ta) é o substrato mais indicado para a espécie em questão.

A sobrevivência das mudas foi influenciada pelos substratos, sendo a maior percentagem de plantas vivas observada nos substratos LVd (tm) e LVd (ta) e a menor no LVd (tm) + OR (Tabela 3). Para essa característica, o efeito menos favorável do substrato LVd (tm) + OR é marcante, havendo diminuição de $45 \%$ de sobrevivência entre $\mathrm{LVd}$ (tm) e LVd (tm) + OR. A adição de Organosuper ${ }^{\circledR}$ ao substrato $\mathrm{LVd}$ (tm) aumentou consideravelmente os níveis de $\mathrm{pH}$ e fósforo, e elevou a saturação de bases de $14 \%$ para $83 \%$ (Tabela 1). O pH do solo tem grande influência na disponibilidade dos micronutrientes, havendo a diminuição da solubilização e a absorção de $\mathrm{Cu}, \mathrm{Zn}, \mathrm{Fe}$ e $\mathrm{Mn}$, à medida que se eleva o $\mathrm{pH}$ do solo (DECHEN; NATCHTIGAL, 2006). Pode-se considerar que as prováveis alterações das características químicas, físicas e biológicas no substrato, promovidas pela adição de Organosuper®, não foram adequadas para a fase de produção de mudas, provavelmente em função do desequilíbrio nutricional face à provável diminuição de disponibilidade de micronutrientes pelo aumento do $\mathrm{pH}$.

O IQD (Tabela 4) foi maior nos substratos LVd (ta) e LVd (tm). Como este índice relaciona as características das mudas da parte aérea e das raízes, o mesmo indica que, nesses substratos, as mudas estavam mais vigorosas. É provável que as mudas de guavira se desenvolvam melhor em solos mais ácidos, especialmente de textura argilosa. Costa et al. (2010), ao avaliarem o crescimento de mudas de guavira, em Jataí (GO), em solo natural sem calagem, solo natural com calagem para atingir $\mathrm{V}=40 \%$ e solo natural com calagem para $\mathrm{V}=70 \%$, observaram que, com calagem para $\mathrm{V}=70 \%$, as alturas de plantas, diâmetro do coleto e número de folhas foram menores. Os autores consideraram o resultado esperado, por considerarem a guavira uma espécie que se desenvolve melhor em solos mais ácidos; no entanto, não forneceram os dados das análises químicas e físicas referentes aos solos, mas supõe-se tratar-se de solo ácido de Cerrado. 


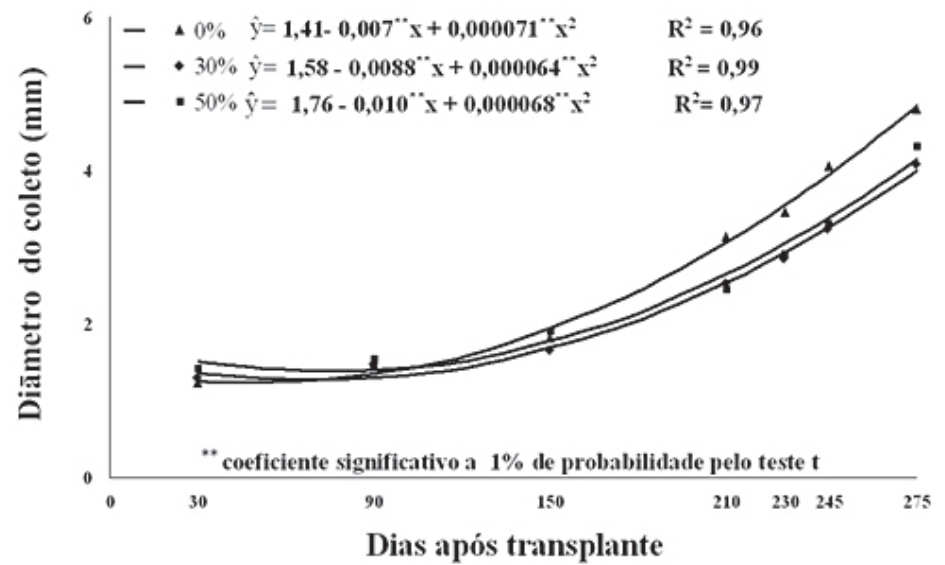

FIGURA 1 - Diâmetro do coleto de plantas de guavira influenciado pelos níveis de sombreamento $(0 \%$, $30 \%$ e $50 \%$ de sombra) e dias após transplante, Campo Grande-MS..


FIGURA 2 - Largura (a) e comprimento (b) de folhas de mudas de guavira influenciadas pelos níveis de sombreamento $(0 \%, 30 \%$ e $50 \%$ de sombra) e dias após transplante, Campo Grande-MS. 


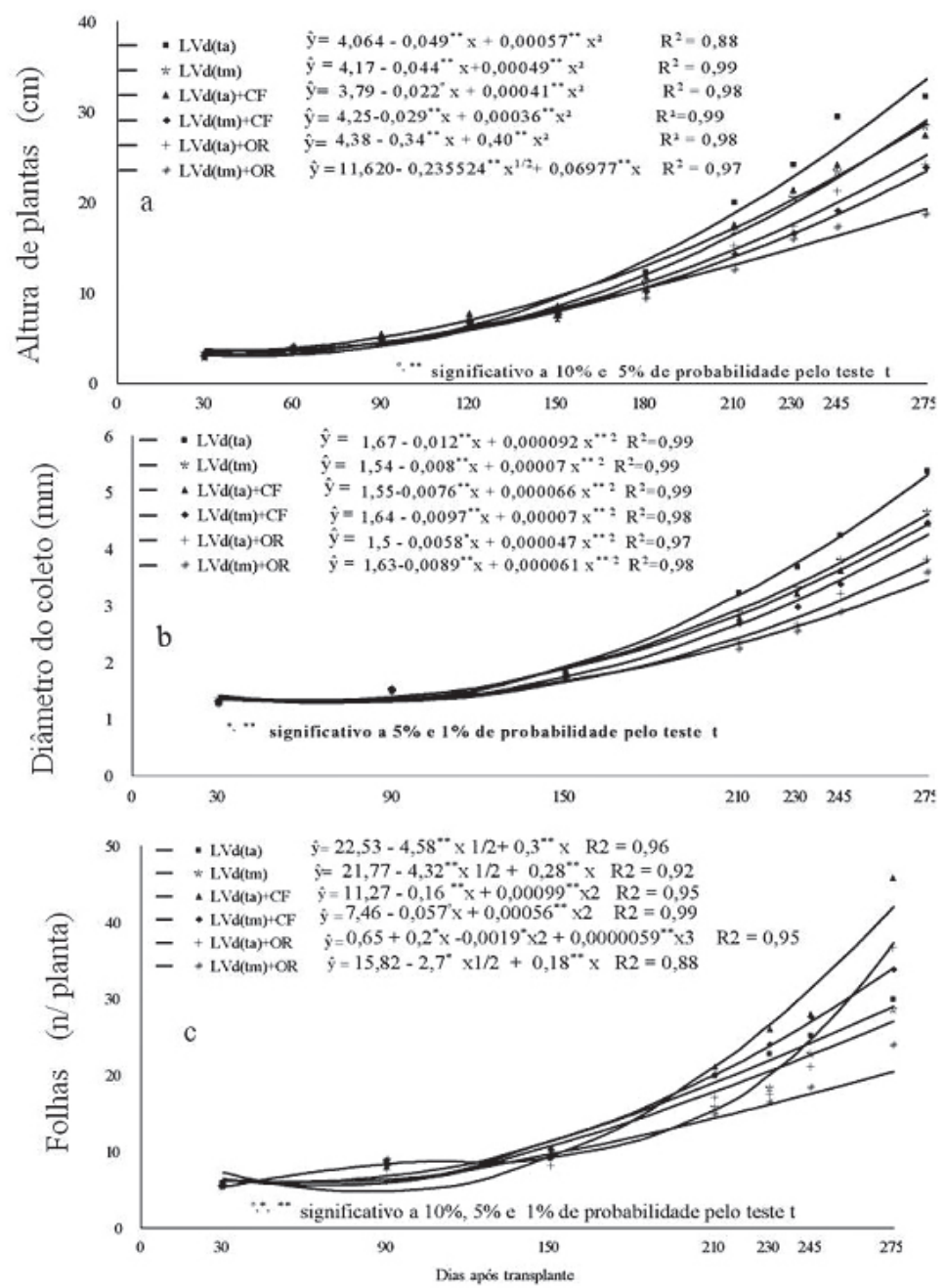

FIGURA 3 - Altura (a), diâmetro do coleto (b) e número de folhas (c) de plantas de guavira cultivadas em diferentes substratos, no período de 275 dias, Campo Grande-MS.

TABELA 1 - Análise química - ${ }^{1}$ dos diferentes substratos, Campo Grande-MS.

\begin{tabular}{cccccccccccc}
\hline Substrato & $\mathbf{M . O}$ & $\mathbf{p H}$ & $\mathbf{P}$ & $\mathbf{K}$ & $\mathbf{A l}$ & $\mathbf{C a}$ & $\mathbf{M g}$ & $\mathbf{H}+\mathbf{A l}$ & $\mathbf{S}$ & $\mathbf{T}$ & $\mathbf{V}$ \\
\hline & $\mathrm{g} \mathrm{dm}^{-3}$ & $\mathrm{Ca} \mathrm{Cl}_{2}$ & $\mathrm{mg} \mathrm{dm}^{-3}$ & & ---------- & $\mathrm{cmol} \mathrm{dm}^{-3}----------$ & & $\%$ \\
\hline LVd (ta) & 37,9 & 4,4 & 2 & 0,3 & 0,6 & 1,5 & 0,8 & 8,5 & 2,6 & 11,1 & 23 \\
LVd (tm) & 24,1 & 4,5 & 4 & 0,1 & 0,9 & 0,9 & 0,2 & 7,2 & 1,2 & 8,4 & 14 \\
LVd (ta) + CF & 32,5 & 6,4 & 319 & 5,2 & 0,0 & 2,5 & 3,5 & 2,4 & 11,2 & 13,6 & 82 \\
LVd (tm) + CF & 29,0 & 6,4 & 209 & 2,2 & 0,0 & 3,0 & 1,9 & 2,8 & 7,1 & 9,9 & 71 \\
LVd(ta) + OR & 33,7 & 6,4 & 281 & 1,1 & 0,0 & 3,5 & 3,1 & 2,4 & 7,7 & 10,1 & 76 \\
LVd (tm) + OR & 38,5 & 7,0 & 505 & 1,4 & 0,0 & 3,4 & 3,5 & 1,6 & 8,3 & 9,9 & 83 \\
\hline
\end{tabular}

${ }^{1}$ Análise feita no Laborátório de solos da FCA-UFGD

P Mehlich I 
TABELA 2 - Massa seca de raízes por kg de solo (MSR), razão de área foliar (RAF), área foliar específica (AFE) e razão de peso da folha (RPF) de mudas de guavira desenvolvidas sob diferentes níveis de sombreamento, Campo Grande-MS.

\begin{tabular}{cccccc}
\hline Sombreamento $(\%)$ & MSR $\left(\mathrm{g} \mathrm{kg}^{-1}\right)$ & RAF & AFE & RPF & VIVAS $\%$ \\
\hline 0 & $0,83 \mathrm{a}$ & $3,50 \mathrm{c}$ & $8,03 \mathrm{c}$ & $0,44 \mathrm{~b}$ & 72,22 \\
30 & $0,50 \mathrm{~b}$ & $4,80 \mathrm{~b}$ & $9,90 \mathrm{~b}$ & $0,48 \mathrm{a}$ & 77,78 \\
50 & $0,49 \mathrm{~b}$ & $5,54 \mathrm{a}$ & $10,86 \mathrm{a}$ & $0,50 \mathrm{a}$ & 83,33 \\
\hline Média & 0,60 & 4,61 & 9,60 & 0,48 & 77,78 \\
\hline CV $(\%)$ & 43,44 & 18,46 & 10,40 & 12,72 & 12,78 \\
\hline
\end{tabular}

Médias seguidas pelas mesmas letras, nas colunas, não diferem, pelo teste Scott-Knott, a 5\% de probabilidade.

TABELA 3 - Altura de plantas; massa seca de caule (MSC), folhas (MSF) e raízes (MSR); número de folhas (NF), área foliar (AF), porcentagem de sobrevivência (vivas) e massa seca de raiz de mudas de guavira desenvolvidas em seis diferentes substratos, aos 275 DAT, Campo Grande-MS.

\begin{tabular}{cccccccc}
\hline Substrato & Altura & MSC & MSF & MSR & NF & AF & Vivas \\
\hline & cm & $-------g /$ planta ----- & g/kg solo & unid & cm²/planta $^{2}(\%)$ \\
\hline LVd(ta) & $31,71 \mathrm{a}$ & $1,98 \mathrm{a}$ & $5,62 \mathrm{a}$ & $1,41 \mathrm{a}$ & $30,00 \mathrm{~b}$ & $481,21 \mathrm{~b}$ & $95,55 \mathrm{a}$ \\
LVd(tm) & $28,46 \mathrm{a}$ & $1,42 \mathrm{~b}$ & $3,91 \mathrm{~b}$ & $0,73 \mathrm{~b}$ & $28,30 \mathrm{~b}$ & $353,30 \mathrm{c}$ & $98,88 \mathrm{a}$ \\
LVd (ta)+CF & $27,34 \mathrm{a}$ & $2,33 \mathrm{a}$ & $6,74 \mathrm{a}$ & $0,55 \mathrm{~b}$ & $45,81 \mathrm{a}$ & $659,61 \mathrm{a}$ & $82,22 \mathrm{~b}$ \\
LVd(tm)+CF & $23,85 \mathrm{~b}$ & $1,92 \mathrm{a}$ & $5,33 \mathrm{a}$ & $0,35 \mathrm{c}$ & $33,89 \mathrm{~b}$ & $470,27 \mathrm{~b}$ & $64,45 \mathrm{c}$ \\
LVd(ta)+OR & $24,16 \mathrm{~b}$ & $1,67 \mathrm{~b}$ & $4,43 \mathrm{~b}$ & $0,36 \mathrm{c}$ & $36,70 \mathrm{a}$ & $421,48 \mathrm{~b}$ & $70,00 \mathrm{c}$ \\
LVd(tm)+OR & $18,70 \mathrm{c}$ & $0,80 \mathrm{c}$ & $2,16 \mathrm{c}$ & $0,22 \mathrm{c}$ & $23,96 \mathrm{~b}$ & $220,55 \mathrm{c}$ & $54,44 \mathrm{~d}$ \\
\hline Média & 25,71 & 1,69 & 4,70 & 0,60 & 33,17 & 434,41 & 77,76 \\
\hline CV (\%) & 18 & 39 & 36 & 43,44 & 29 & 34 & 14,12 \\
\hline
\end{tabular}

Médias seguidas pelas mesmas letras, nas colunas, não diferem, pelo teste Scott-Knott,a 5\% de probabilidade.

TABELA 4 - Índice de qualidade de Dickson (IQD) em mudas de guavira desenvolvidas em diferentes substratos, Campo Grande-MS.

\begin{tabular}{lc}
\hline \multicolumn{1}{c}{ Substrato $^{5}$} & IQD \\
\hline LVd (ta)- & $2,62 \mathrm{a}$ \\
LVd (tm) - & $1,50 \mathrm{a}$ \\
LVd (ta) $+\mathrm{CF}$ & $1,43 \mathrm{~b}$ \\
LVd $(\mathrm{tm})+\mathrm{CF}$ & $1,08 \mathrm{c}$ \\
$\mathrm{LVd}(\mathrm{ta})+$ OR & $0,94 \mathrm{c}$ \\
LVd (tm) + OR & $0,61 \mathrm{c}$ \\
\hline Média & 1,36 \\
\hline CV $(\%)$ & 41,93 \\
\hline
\end{tabular}

Médias seguidas pelas mesmas letras, nas colunas, não diferem, pelo teste Scott-Knott, a $5 \%$ de probabilidade.

\section{CONCLUSÕES}

1-As mudas de Campomanesia adamantium podem ser cultivadas sob sombreamento de $50 \%$.

2-A utilização do substrato com $100 \%$ de solo Latossolo Vermelho distrófico, textura argilosa, é o mais indicado para a produção de mudas de $C$. adamantium.

\section{AGRADECIMENTOS}

Ao CNPq, pelo auxílio financeiro, à Fundect, pela bolsa de doutorado, e à Organoeste, pela doação do composto orgânico Organosuper $\circledR$. 


\section{REFERÊNCIAS}

AJAllA, A. C. A.; VOlPE, E.; VIEIRA, M. C. V.; ZÁRATE, N. A. H. Produção de mudas de baru (dipteryx alata Vog.) sob três níveis de sombreamento e quatro classes texturais de solo. Revista Brasileira de Fruticultura, Jaboticabal, v. 34, n.3, p. 888-896, 2012.

BENINCASA, M. M. P. Análise do crescimento de plantas: noções básicas. Jaboticabal: FUNEP, 2003. 42 p.

BINOTTO, A. F. Variação entre variáveis de crescimento e o índice de qualidade de Dickson em mudas de Eucalyptus grandis W. Hillm ex Maid e Pinnus elliottii var. elliottii Engelm, 2007. 56f. Dissertação (Mestrado em Engenharia Florestal -Manejo Florestal) - Universidade Federal de Santa Maria, Santa Maria, 2007.

BINOTTO, A.F.; LÚCIO, D. C. A.; LOPES, S. J. Betwen growth variables and the Dickson quality índex in Forest seedling. Cerne, Lavras, v. 16, n. 4, p.457 - 464, 2010.

COSTA, E. ; LEAL, P. A. M.; REGO, N. H. ; BENATTI, J. Desenvolvimento inicial de mudas de jatobazeiro do cerrado em Aquidauana-MS. Revista Brasileira de Fruticultura, Jaboticabal, v. 33, n. 1, p. 215-226, 2011.

COSTA, E.; SILVA, P. N. de L.; JORGE, M. H. A.; FERREIRA, A. F. Guavira Emergence And Seedling Production With Substrates Containing Organic Compost And Soil Under Different Screen Environments. Revista Brasileira de Fruticultura, Jaboticabal, v. 34, n. 4, p.1289-1293, 2012.

COSTA, M. K. F.; REIS, E. F. dos; PINTO, J. F. N. Efeito da calagem e adubação potássica e fosfatada em Campomanesia spp (MYRTACEAE). In: CONGRESSO DE PESQUISA E EXTENSÃO, 7. 2010, Goiânia. Resumos... Goiânia: UFG. Disponível em: <http://www.sbpcnet.org.br/livro/63ra/conpeex/ trabalhos-pivic/MELISA K.PDF $>$. Acesso em: 24 jan. 2012.

DECHEN, A. R.; NACHTIGALL, G. R. Micronutrientes. In $>$ FERNANDES, M. S. (Ed.). Nutrição mineral de plantas. Viçosa: Sociedade Brasileira de Ciência do Solo, 2006. p.327.
DRESCH, D. M. ;SCALON, S. P. Q.; MASETTO, T. E.; VIEIRA, M.C. Germinação de sementes de Campomanesia adamantium (Camb.) O. Berg em diferentes temperaturas e umidades do substrato. Scientia Forestalis, Piracicaba, v.40, p. 223-229, 2012.

ENGEL. V. L.; POGGIANI, F. Influência do sombreamento sobre o crescimento de mudas de algumas essências nativas e suas implicações ecológicas e silviculturais. IPEF, Piracicaba, v.43 n.44, p.1-10, 1990.

FONSECA, E. de P.; VALÉRI, S. V.; MIGLIORANZA, E.; FONSECA, N. A. N.; COUTO, L. Padrão de qualidade de mudas de Trama micrantha (L) Blume, produzidas sob diferentes períodos de sombreamento. Revista Árvore, Viçosa, MG, v. 26, n. 4, p. 515-523, 2002 .

GODOY, T. G.; ROSADO, S. C. da S. Estimates of genetic gains for growth traits in Young plants of Eucalyptus urophylla S. T. Blake. Cerne, Lavras, v. 17, n. 2, p. 189-193, 2011.

LARCHER, W. Ecofisiologia vegetal. São Carlos: RIMA, 2006. 550 p.

LORENZI, H.; BACHER, L.; LACERDA, M.; SARTORI, S. Frutas brasileiras e exóticas cultivadas (de consumo in natura). São Paulo: Plantarum, 2006, 640p.

MELCHIOR S.J.; CUSTÓDIO C.C.; MARQUES, N.B. M.N. Colheita e armazenamento de sementes de gabiroba (Campomanesia adamantium Camb Myrtaceae) e implicações na germinação. Revista Brasileira de Sementes, Viçosa, MG, n.28, p.14115, 2006.

PAVAN, F. R.; LEITE, C. Q. F.; CARDOSO, C. de L.; VILEGAS, V.; LEITE, S. R. de A.; SATO, D. N. Evaluation of anti-Mycobacterium Tuberculosis activity of Campomanesia adamantium (Myrtaceae). Quimica Nova, São Paulo, v. 32, n.5, p. 1222-1226, 2009.

REGO, G. M.; PASSAMAR, E. Efeito do Sombreamento sobre o Teor de Clorofila e Crescimento Inicial do Jequitibá-rosa. Boletim de Pesquisa Florestal, Curitiba, n. 53, p.179-194 . 2006. 
SANTOS. R. F; MOARAE, L.; BORSOLI, A.; SECCO, D.; MOREIRA, G.C. Níveis de sombreamento na produção e desenvolvimento de mudas Eucalyptus grandis Hill ex Maiden. Pesquisa Aplicada \& Agrotecnologia, Guarapuava, v.3, n.3, 2010.

SILVA, I. R. da; MENDONÇA, E. de S. Matéria orgânica no solo. In: NOVAES, R. F.; ALVAREZ, V. H. V.; BARROS, N. F. de; FONTES, R. L. F. ; CANTARUTTI, R. B.; NEVES, J. C. L. (Ed.). Fertilidade do solo. Viçosa: Sociedade Brasileira de Ciência do solo, 2007. p.275-374.
SILVA, M. L. S.; VIANA, A. E. S.; JOSÉ, A. R. S.; AMARAL, C. L. F.; MATSUMOTO, S. N.; PELACANI, C. R. Desenvolvimento de mudas de maracujazeiro (Passiflora edulis Sims f. flavicarpa Deg. ) sob diferentes níveis de sombreamento. Acta Scientiarum, Maringá, v. 28, n. 4, p. 513-521, 2006.

VOLPE, E.; MARCHETTI, M. E.; MACEDO, M. C. M.; ROSA JÚNIOR, E. J. Renovação de pastagem degradada com calagem, adubação e leguminosa consorciada em Neossolo Quartzarênico. Acta Scientiarum Agronomy, Maringá, v. 30, n.1, p. 131-138, 2008 